\title{
Teaching child and adolescent psychiatry to medical undergraduates
}

\author{
Anne E. Worrall-Davies
}

The aim of this article is to set the teaching of child and adolescent psychiatry to medical undergraduates in the framework of current educational theory and General Medical Council (1993) curriculum guidelines. The objectives are to:

(a) outline the main reasons for teaching child and adolescent psychiatry in the medical undergraduate curriculum;

(b) discuss placement of child and adolescent psychiatry teaching in the curriculum;

(c) outline relevant content;

(d) describe appropriate teaching methods; and

(e) describe assessment and evaluation procedures.

\section{Why teach child and adolescent psychiatry?}

It is well-known that $20-25 \%$ of children attending a clinic in a primary care or paediatric setting have psychological problems (Fitzgerald, 1985; Bernard \& Garralda, 1995). Since a significant minority of medical students take up a career in general practice, it stands to reason that teaching child and adolescent psychiatry is an important part of training for a career in general practice or paediatrics. However, few have the opportunity at postgraduate level to spend time in child and adolescent psychiatry posts, so teaching the basics of child and adolescent psychiatry at undergraduate level is vital (Cottrell \& Hill, 1988).

\section{What should students learn?}

The design of a module should begin with a needs assessment followed by the setting of learning objectives (Curran \& Bowie, 1998). A needs assessment involves deciding what is appropriate for students to learn. Medical undergraduates need the basics of child and adolescent psychiatry to equip them for a career in primary care, or to be able to communicate effectively with children and families in other clinical settings. Therefore, the learning objectives should be simple, clear and not overinclusive (Box 1). Suggested learning objectives for the teaching of child and adolescent psychiatry to medical undergraduates should also be found in the curriculum documentation of most medical schools.

Box 1. Learning objectives in child and adolescent psychiatry for medical students (core curriculum).

At the end of the teaching block, medical students should:

(a) appreciate the importance of the social and psychological effects on a child and family of normal development and of illness

(b) be able to communicate with children and families in a developmentally appropriate way

(c) describe the prevalence and presentation of common psychological problems in children

(d) have developed a framework for assessing the causes of childhood psychological problems

(e) be able to identify the psychological problems in children which warrant referral to specialist child mental health services and be able to explain the referral process to families 
Augmentation of the core topics should be achieved through 'special study modules' and some suggested additional learning objectives for special study modules relevant to child and adolescent psychiatry are shown in Box 2. Special study modules were recommended by the General Medical Council (1993); they provide an opportunity for promoting independent study in depth, insights into scientific method and the discipline of research, and promote a questioning, self-critical approach to learning. They may be short and focused two-week blocks, or longer 6-8 week blocks with a broad topic base. They may be placed at any point within the undergraduate curriculum.

\section{Where in the curriculum?}

The obvious choices for the placing of child and adolescent psychiatry teaching in the undergraduate curriculum are in either a child health or psychiatry module. There are advantages and disadvantages to both (see Box 3). However, the learning objectives set in Box 1 fit most comfortably into placing the core child and adolescent psychiatry teaching in the child health module, with additional teaching about severe mental illness in children and adolescents within the psychiatry module. The length of time available to child and adolescent psychiatrists to teach medical undergraduates varies widely between medical schools, but the learning objectives set out in this article should be easily achievable even in a short period of teaching contact time. In medical schools where a longer period of time is set aside for child

Box 2. Some additional learning objectives in child and adolescent psychiatry for medical students ('special study modules')

At the end of the special study module medical students should be able to:

(a) make a formulation of the problems presented, and relevant causes and consequences, and recommendations for management

(b) understand the role of different staff disciplines in a team and foster a multidisciplinary approach to patient care

(c) understand the anxieties related to hospital admission for a child or young person and recognise how they can be alleviated
Box 3. Advantages and disadvantages of teaching child and adolescent psychiatry within child health or psychiatry modules in the medical undergraduate curriculum

Child health module:

Advantages

- Encourages clinical liaison between the specialties

- Emphasises understanding the relation between physical and psychological disorders in children

- Emphasises a holistic approach to child health care

Disadvantages

- May be difficult to teach about severe mental illness in children to students who have not completed a psychiatry module

Psychiatry module:

Advantages

- Emphasises the similarities and differences between mental illness in children and adults

- Emphasises the effect on children of parental mental illness

Disadvantages

- Core child and adolescent psychiatry concerned with different range of disorders than adult psychiatry

and adolescent psychiatry, these objectives can be expanded, or some of the suggested objectives in Box 2 might be incorporated.

\section{What should be taught}

The content of child and adolescent psychiatry teaching should contribute directly to the learning objectives, and to core knowledge and skills required by medical students. It should also allow opportunities for the development of other intellectual skills and support other areas of the undergraduate course. The mix of learning domains (knowledge, skills and attitudes) should also be considered. In child and adolescent psychiatry, factual information at undergraduate level is of minor importance; skills (interviewing, communication) and attitudes (awareness of psychological problems) are much more important. For instance, $20 \%$ of the content could be knowledge- 
based, with skills and attitudes-based teaching accounting for $40 \%$ each of the content. It is useful, therefore, to match the content of the teaching both to the learning objectives and learning domains in a matrix. One suggested content-domain matrix is shown in Table 1.

\section{What teaching methods?}

The General Medical Council (1993) recommendation of using a range of technical resources and teaching methods is good practice, but the use of these techniques should be grounded in the learning objectives and content of the module, not just for effect. However, it is likely that a variety of teaching methods is necessary in order to achieve all the learning objectives in most clinical medical specialities, in which a mixture of basic scientific knowledge, and clinical skills and techniques is required. Likewise, involving staff from a variety of professions allied to medicine in teaching helps medical students understand the multi-disciplinary nature of child and adolescent psychiatry. Suggested teaching methods are shown, together with the content, knowledge, skills and attitudes they address, in Table 2.

Practical points also need to be considered. It is impossible to guarantee that a family will keep an assessment appointment ear-marked for observation by students. It is then useful to have a range of alternatives ready, available and rehearsed, such as videos of family assessments, relevant television programmes or role-play/discussion material. Simply sending the students away for a coffee break is not acceptable.

\section{Assessment and evaluation}

Assessment should follow on from the teaching methods used. It is poor teaching practice to use

Table 1. Content-domain matrix for child and adolescent psychiatry teaching to medical undergraduates

Learning objective
Appreciate the
importance of the social
and psychological effects
on a child and family of
normal development and
and of illness
Communicate with
children and families in a
developmentally
appropriate way
Develop a framework
for assessing the causes of
of childhood psychological
problems

Identify the psychological problems in children warranting referral to specialist child mental health services; explain the referral process to families

Descibe prevalance and presentation of common psychological problems in children

Knowledge
Epidemiology of
psychological problems
in chronic childhood
disease

Skill

Interviewing techniques

Basic child development should already be known - review only

Introduce concept of:
predisposing, precipitating
perpetuating factors of
disorders; individual
child, family and
enviromental influences
on disorders
framework and make a formulation; clarify to families

\section{Attitudes}

Recognition that social and psychological factors affect child emotional and physical development
Integrate the relevant information gathered at interview into the

Interviewing techniques

Integrate relevant information gathered at interview into the framework

Open attitude to detecting
Epidemiology and presentation of common childhood psychological problems psychological problems in primary care

Recognise the need to use varied communication skills to acheive rapport with child and family

Broad understanding of the interaction of social, biological and psychological factors in children

Awareness of how common psychological problems are in primary care and paediatric practice 
Table 2. Appropriate teaching methods and assessment procedures to address identified learning objectives and learning domains

\begin{tabular}{|c|c|c|}
\hline Teaching method & $\begin{array}{l}\text { Learning objective } \\
\text { acheived (see Box 1) }\end{array}$ & Learning domain \\
\hline $\begin{array}{l}\text { 'Live' observation of } \\
\text { family assessment }\end{array}$ & $a, b, c, d, e$ & $\begin{array}{l}\text { Predominantly } \\
\text { skills and attitudes }\end{array}$ \\
\hline $\begin{array}{l}\text { Video or TV programme } \\
\text { of assessment/treatment } \\
\text { package }\end{array}$ & $a, b, c, d, e$ & $\begin{array}{l}\text { Predominantly } \\
\text { skills and attitudes }\end{array}$ \\
\hline Role-play with discusson & $\mathrm{a}, \mathrm{c}, \mathrm{d}, \mathrm{e}$ & $\begin{array}{l}\text { Predominantly } \\
\text { skills and attitudes }\end{array}$ \\
\hline $\begin{array}{l}\text { Porblem-based learning } \\
\text { vignettes }\end{array}$ & $\mathrm{a}, \mathrm{c}, \mathrm{d}, \mathrm{e}$ & $\begin{array}{l}\text { Knowledge and } \\
\text { attitudes }\end{array}$ \\
\hline Seminar & $a, c, d, e$ & $\begin{array}{l}\text { Predominantly } \\
\text { knowledge }\end{array}$ \\
\hline Lecture & $a, c$ & $\begin{array}{l}\text { Predominantly } \\
\text { knowledge }\end{array}$ \\
\hline
\end{tabular}

Assessment procedure

Written case report; oral presentation; OSCES

Worksheet based on TV/ video material completed at the time

Individual participation in discussion group

Completed problem-based task sheet

Multiple choice questions; short answer questions; essay

\section{References}

skills-based teaching and then set a knowledgebased multiple choice test, for instance. The General Medical Council (1993) clearly set out that assessment procedures should have less emphasis on uncritical acquisition of facts. Assessment should be imaginative and appropriate. Table 2 shows some techniques relevant to child and adolescent psychiatry. Box 4 provides a summary of the key points to remember in the planning, delivery and evaluation of teaching child and adolescent psychiatry to medical undergraduates.

Box 4. Key points

Teaching child and adolescent psychiatry is important for medical undergraduates

Setting clear basic learning objectives at the start is essential

Do not be over-inclusive or over-ambitious with content

Emphasise the acquisition of skills and attitudes rather than content

Use a variety of teaching methods when and where appropriate to achieve objectives

Be innovative with techniques to assess skills and attitudes
Bernard, P. \& Garralda, M. E. (1995)Child and adolescentmental health practice in primary care. Current Opinion in Psychiatry, 8, 206-209. Cottrell, D. J. \& Hill, P. D. (1988) Child psychiatry and the undergraduate. Archives of Disease in Childhood, 63, 3-4.

Curran, S. \& Bowie, P. C. W (1998) Teaching psychiatry to medical undergraduates. Advances in Psychiatric Treatment, 4, 167-171.

Fitzgerald, M. (1985) Behavioural deviance and maternal depressive symptoms in paediatric outpatients. Archives of Disease in Childhood, 60, 560-562.

General Medical Council (1993) Tomorrow's Doctors: Recommendations on Undergraduate Medical Education. London: GMC.

\section{Multiple choice questions}

1. The choice of content should be led by:

a the amount of time available on the course

b the special interests of the teachers

c the learning objectives for the course

$\mathrm{d}$ the needs assessment.

2. A needs assessment is:

a the first step in designing a child and adolescent psychiatry course for medical students

b a re-working of previous course material

c carried out after the learning objectives have been set 
d not required if you feel confident about what you teach to medical students.

3. Innovative teaching methods:

a are particularly difficult to introduce in child and adolescent psychiatry teaching

b should always be used

c should reflect the learning objectives

d are best used as part of a variety of teaching methods to achieve the learning objectives.

4. Key points for medical undergraduates to appreciate in child and adolescent psychiatry are:

a how to communicate effectively with children and families

b how to recognise common psychological problems c how to diagnose conditions using ICD-10 criteria

d how to plan a behavioural programme for the treatment of exam phobia.

\begin{tabular}{|c|c|c|c|c|c|c|c|}
\hline \multicolumn{8}{|c|}{ MCQ answers } \\
\hline 1 & & 2 & & 3 & & 4 & \\
\hline & $\mathrm{T}$ & a & $\mathrm{T}$ & a & $F$ & a & $T$ \\
\hline b & F & b & F & b & F & b & $\mathrm{T}$ \\
\hline c & $\mathrm{T}$ & c & F & c & $\mathrm{T}$ & c & F \\
\hline d & $\mathrm{T}$ & d & F & d & $\mathrm{T}$ & d & F \\
\hline
\end{tabular}

